\title{
Antagonism of the Antibacterial Action of Some Penicillins by Other Penicillins and Cephalosporins
}

\author{
J. F. Acar, L. D. SAbath, and P. A. Ruch \\ From Channing Laboratory, Thorndike Memorial Laboratory, Harvard Medical \\ Unit, and Department of Medical Bacteriology, Boston City Hospital, and \\ Department of Medicine, Harvard Medical School, Boston, Massachusetts 02118
}

A в S T R A C T There are many examples of two penicillins acting synergistically, usually by one competitively inhibiting $\beta$-lactamase, thus protecting the other from inactivation. There are few reports on penicillins antagonizing each other. Eight strains of three genera (Proteus, Escherichia, Pseudomonas) isolated at Boston City Hospital or Institut Pasteur, Paris, showed antagonism of carbenicillin or ampicillin by cephaloridine, cloxacillin, or 6-aminopenicillanic acid. Broth dilution tests showed that with seven of the eight strains the minimum inhibiting concentration (MIC) of the more active antibiotic was increased by $800-6,400 \%$ by low concentrations (often one-tenth the MIC) of the antagonist, whereas higher concentrations of "antagonist" were not as antagonistic. This suggested that two or more receptor sites of action for penicillins were present; the antagonist thus blocks the antibacterial action at the more sensitive site but acts additively with the antagonized antibiotic at the less sensitive site. The possibility that the mechanism of antagonism was induction of inactivating enzymes ( $\beta$-lactamase, penicillin acylase) was studied in two strains (one Escherichia coli and one Proteus rettgeri), and two antagonists were studied in detail. With $E$. coli cephaloridine was a poorer inducer of $\beta$-lactamase than were the antagonized antibiotic and 6-aminopenicillanic acid. From these orga-

Presented in part at the 11th Interscience Conference on Antimicrobial Agents and Chemotherapy, Atlantic City, N. J., 21 October 1971.

Dr. Sabath was a recipient of a Career Development Award from the National Institute of Allergy and Infectious Diseases while some of these studies were in progress. Dr. Acar's present address is the Institut Pasteur, Paris $15^{\circ}$, France. Dr. Sabath's present address is the Mayo Memorial Building, University of Minnesota, Minneapolis, Minn. 55455.

Received for publication 12 June 1974 and in revised form 10 October 1974. nisms, the good inducers of a $\beta$-lactamase that acted on benzylpenicillin did not induce enzymes that inactivated carbenicillin. Thus, the mechanism of antagonism was not due to $\beta$-lactamase induction.

\section{INTRODUCTION}

The antibacterial activity of penicillins and cephalosporins is due to their inhibition of normal cell wall formation $(1,2)$. When more than one penicillin is present in a solution or medium with bacteria, there is fairly clear evidence that they compete with each other for binding by the bacteria (3). The tacit assumption is that once a penicillin gets on its binding site its action is the same as any other penicillin; differences in the minimum inhibiting concentration (MIC) ${ }^{1}$ of one penicillin compared with another appear to correlate rather well with differences in their affinities for a critical binding site ( 3 ).

A number of authors have reported that a synergistic antibacterial effect may result when two penicillins or a penicillin and a cephalosporin are used in combination against certain gram-negative bacilli(4-7). The mechanism for this synergistic effect was shown to be a competitive inhibition of a $\beta$-lactamase (penicillinase, E.C. 5.1.2.6) by one of the penicillins, which protected the second penicillin from inactivation by hydrolysis and thus permitted it to exert its antibacterial effect $(4,8)$. The less active antibiotic of the synergistic pair is usually highly resistant to the $\beta$-lactamase for which it has a markedly greater affinity (9).

In the course of testing various antibiotic pairs against many gram-negative bacilli for possible synergy, it was independently noted in Boston (by Sabath) and in Paris (by Acar) that a few strains not only failed to

\footnotetext{
${ }^{1}$ Abbreviation used in this paper: MIC, minimum inhibiting concentration.
} 
TABLE I

MIC of Indicated Antibiotics Alone and in Combination

\begin{tabular}{|c|c|c|c|c|c|c|c|c|}
\hline Antibiotic & E. coli & P. aeruginosa I & $P$. aeruginosa II & $P$. rettgeri & P. morganii I & P. morganii II & P.vulgaris I & P. vulgaris II \\
\hline & & & & $\mu g / m l$ & & & & \\
\hline Carbenicillin & 8 & 8 & 125 & 8 & 4 & 4 & 64 & 16 \\
\hline 6-APA & 64 & 1,000 & - & 500 & 1,000 & 500 & 125 & 125 \\
\hline $\begin{array}{c}\text { Carbenicillin }+ \\
\text { (6-APA) }\end{array}$ & & & - & & & (50) $256 *$ & (50) $256 *$ & (25) $128 *$ \\
\hline Cephaloridine & $\begin{array}{c}(10) \mp 128 * \\
500\end{array}$ & $\begin{array}{l}(50) 1^{128 *} \\
-\end{array}$ & - & $\begin{array}{l}\text { (25) } 256^{*} \\
500\end{array}$ & $\begin{array}{c}(50) 256^{*} \\
-\end{array}$ & $\begin{array}{c}(50) 256^{*} \\
-\end{array}$ & $\begin{array}{c}\text { (50) } 250^{*} \\
1,000\end{array}$ & - \\
\hline $\begin{array}{l}\text { Carbenicillin }+ \\
\text { (cephaloridine) }\end{array}$ & (50) $128 *$ & - & - & (50) $64 *$ & - & - & (125) $500 *$ & - \\
\hline $\begin{array}{l}\text { 7-ACA } \\
\text { Carbenicillin + }\end{array}$ & 250 & $>1,000$ & - & $>1,000$ & - & - & - & $>1,000$ \\
\hline$(7-A C A)$ & (50) $128^{*}$ & $(100$ or 250$) 8$ & - & $(100$ or 250$) 32 *$ & - & - & 一 & $(100$ or 250$) 32$ \\
\hline BLP 1654 & - & 4 & 一 & 16 & - & - & - & - \\
\hline BLP $1654+$ & & & & & & & & \\
\hline $\begin{array}{c}\text { (6-APA) } \\
\text { Benzylpenicillin }\end{array}$ & $=$ & $\begin{array}{l}(25) \\
>2,000\end{array}$ & 二 & $\begin{array}{l}\text { (25) } 128^{*} \\
1,000\end{array}$ & 二 & 二 & -500 & 二 \\
\hline Methicillin & - & 1,000 & - & - & - & - & - & - \\
\hline $\begin{array}{l}\text { Benzylpenicillin } \\
\text { (methicillin) }\end{array}$ & - & (100) 1,0008 & - & - & - & - & - & - \\
\hline $\begin{array}{l}\text { Benzylpenicillin }+ \\
\quad(6-A P A)\end{array}$ & - & - & - & $(25)>2,000 *$ & - & 一 & (50) $2,000 *$ & - \\
\hline $\begin{array}{l}\text { Cloxacillin } \\
\text { Carbenicillin }+\end{array}$ & 250 & $>1,000$ & $>1,000$ & 500 & - & - & - & 250 \\
\hline $\begin{array}{c}\text { Carbenicillin }+ \\
\text { (cloxacillin) }\end{array}$ & - & - & (10) 250 & (250) 4 & - & 一 & - & - \\
\hline $\begin{array}{l}\text { Ampicillin } \\
\text { Ampicillin }+\end{array}$ & 8 & $>1,000$ & - & 32 & 32 & - & - & 16 \\
\hline (cloxacillin) & (100) 4 & - & - & (250) 32 & - & - & - & - \\
\hline$\underset{\text { (6-APA) }}{\text { Ampicillin }+}$ & - & - & - & - & - & - & - & (12.5) 64* \\
\hline
\end{tabular}

6-APA, 6-aminopenicillanic acid; 7-ACA, 7-aminocephalosporanic acid.

* Antagonism (fourfold or greater increase in MIC of more active antibiotics).

$\ddagger$ Number in parentheses indicates concentration of less active antibiotics being tested for antagonistic or synergistic effect.

\& Synergy.

show synergy but that there was striking antagonism. It is the purpose of this report to describe the phenomenon and to describe studies conducted to elucidate the possible mechanism of antagonism.

\section{METHODS}

Bacteria. The eight strains studied were isolated in the diagnostic bacteriology laboratories at either Boston City Hospital (by or under the supervision of A. Kathleen Daly or Alice McDonald) or Institut Pasteur, Paris. These were one strain Escherichia coli, two Pseudomonas aeruginosa, one strain Proteus rettgeri, and two strains each of Proteus vulgaris and Proteus morgani.

Antibiotic susceptibility tests. Quantitative susceptibilities were determined by a broth dilution test in Difco brain heart infusion broth with inocula of approximately $10^{5}$ colony-forming units per $\mathrm{ml}$; after incubation at $37^{\circ} \mathrm{C}$ for $16-20 \mathrm{~h}$ those inoculated tubes failing to show turbidity were considered to contain the MIC of the antibiotic or antibiotics in that tube. Paper disks (Schleicher \& Schuell, Inc., Keene, N. H., no. 740-E) or filter paper strips (Whatman no. 2) containing known amounts of antibiotic were placed on the surface of Difco heart infusion agar seeded with $0.1 \mathrm{ml}$ of overnight cultures of organisms (diluted $10^{-2}$ with brain heart infusion) and incubated $16-20 \mathrm{~h}$ at $37^{\circ} \mathrm{C}$ to qualitatively determine susceptibility.

Synergy and antagonism. Pairs of antibiotics were tested for possible synergy or antagonism by two techniques: $(a)$ a "checkerboard" arrangement of varying combinations of each of the two antibiotics in brain heart infusion broth in test tubes was prepared, each was inoculated with the organism to be tested, and the results after $18-20 \mathrm{~h}$ at $37^{\circ} \mathrm{C}$ were plotted on an isobologram (9-11); and (b) filter paper strips or disks to which single antibiotics had been added were placed near other strips or disks containing a second antibiotic on the surface of heart infusion agar seeded with the organism to be tested; after $18-20 \mathrm{~h}$ at $37^{\circ} \mathrm{C}$ zones of inhibition developed around some of the strips or disks, but the shape of these zones was distorted and reduced in size if the antibacterial activity was antagonized by the substance diffusing from the neighboring strip or disks.

Inactivation of antibiotic and $\beta$-lactamase assays. The inactivation of carbenicillin by whole cells in liquid was determined by assaying at various times of incubation the antibiotic in Millipore ( $0.3 \mu \mathrm{m}$ pore size) (Millipore Corp., Bedford, Mass.) filtrates with an agar diffusion method (12) in which the assay organism was $P$. aeruginosa NCTC 10490. Qualitative tests for $\beta$-lactamase activity were performed by the Haight-Finland (13) modification of Gots test (14). Quantitative measurements of $\beta$-lactamase activity were performed manometrically $(15,16)$ on whole cells, culture supernatant fluids, and on cells disrupted with the sonic probe (Sonifier Cell Disruptor, Ultrasonics, Plainview, N. J.) or with Ballotini beads in the MSK cell homogenizer (VWR Scientific Div., VWR United Corp., Rochester, N. Y.).

Antibiotic media and reagents. The antibiotics used were donated by the suppliers: ampicillin, 6-aminopenicillanic acid, oxacillin, BLP 1654, and methicillin (Bristol Laboratories, Syracuse, N. Y.); carbenicillin (Beecham-Massen- 


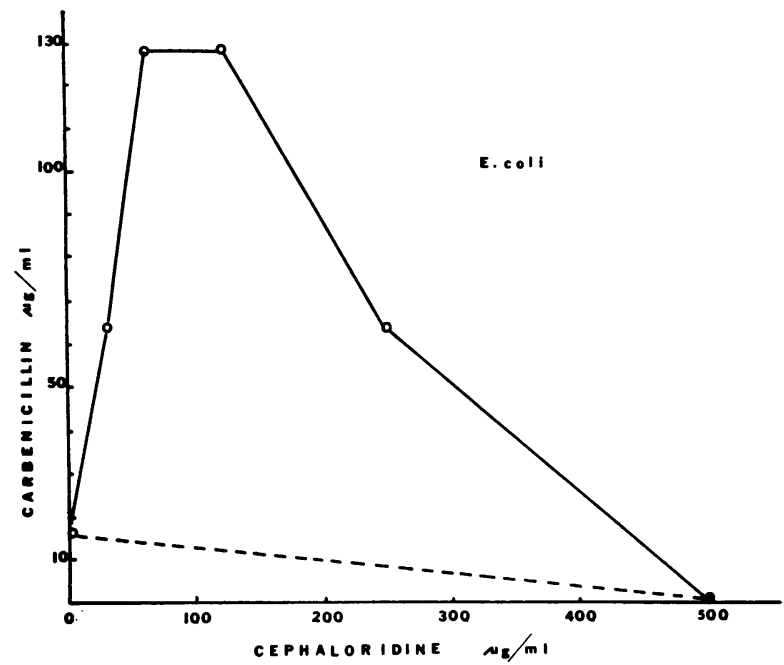

FIGURE 1 Isobologram showing variation in concentration of carbenicillin and cephaloridine required to inhibit growth of $E$. coli when incubated together as a combination at $37^{\circ} \mathrm{C}$. Each point indicates the minimum concentration of one of the two antibiotics required to inhibit this organism when incubated with the indicated concentration of the other (a "combined MIC"). The observed experimental isobol is the solid line connecting all the points. The fact that it is deviated away from the coordinates indicates antagonism. The dotted line connecting the two points on the coordinates (the points representing the MIC of each drug acting alone) is the theoretical isobol for an additive effect.

gill Pharmaceuticals, Clifton, N. J.) ; benzylpenicillin (E. R. Squibb \& Sons, New Brunswick, N. J.) ; cloxacillin (Ayerst Laboratories, New York); and cephalothin, cephaloridine, and 7-aminocephalosporanic acid (Eli Lilly Laboratories for

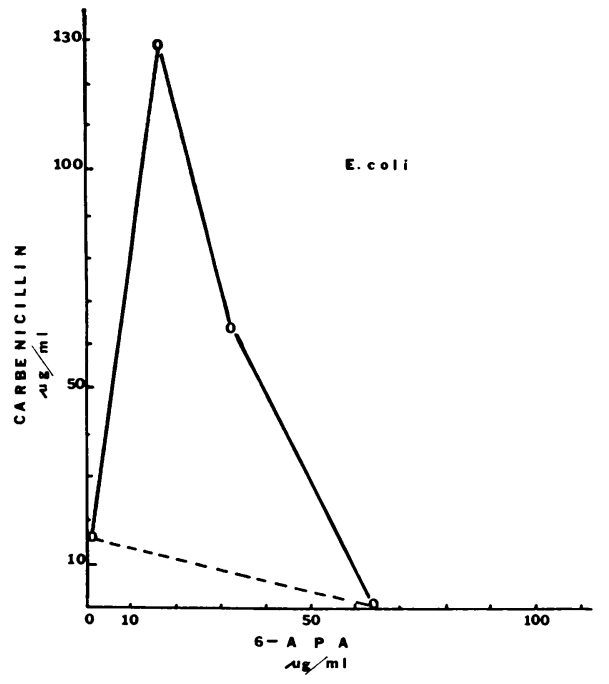

FIGURE 2 Isobologram for $E$. coli in presence of various concentrations of carbenicillin and 6-aminopenicillanic acid (6-APA). Interpretation as in Fig. 1.

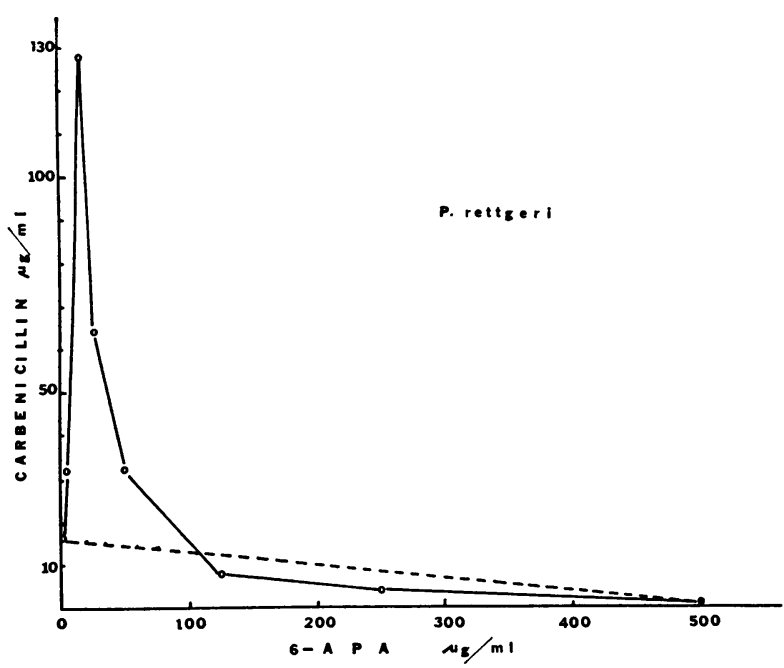

FIGURE 3 Isobologram showing effect of carbenicillin and 6-aminopenicillanic acid (6-APA) in combination on the inhibition of $P$. rettgeri. Interpretation essentially as in Fig. 1 ; note concavity of isobol to right of peak, which indicates synergy between peak and extreme right point (MIC of 6-aminopenicillanic acid alone).

Clinical Research, Indianapolis, Ind.). The brain heart infusion broth, trypticase soy broth, and heart infusion agar were all purchased from Difco Laboratories (Detroit, Mich.). Chemicals were all reagent grade purchased from commercial suppliers.

Protein determination. The protein content in $\beta$-lact?mase preparations was determined by the method of Lowry, Rosebrough, Farr, and Randall (17).

\section{RESULTS}

The MIC of various antibiotics alone and in combination for the study organisms are shown in Table I. Note that only some of the combinations produced antagonism, and each of these instances is marked by an asterisk. There were striking examples of antagonism for seven of the eight organisms, with carbenicillin being antagonized by 6 -aminopenicillanic acid and sometimes by cephaloridine.

The details of three of these examples are presented as isobolograms in Figs. 1-3. The divergence of the isobol upward away from the theoretical additive isobol (the dotted straight line connecting the two points representing the MIC of each antibiotic alone) indicates antagonism. For both the E. coli and the P. rettgeri strains in these figures the maximal antagonism was such that 8 times as much of the more active antibiotic (carbenicillin) was required to inhibit the bacteria, compared to what was required when carbenicillin was present alone. However, in some experiments with P. morgani (Table I) there was a 64 -fold increase in MIC for carbenicillin in the presence of 6-aminopenicillanic acid. 

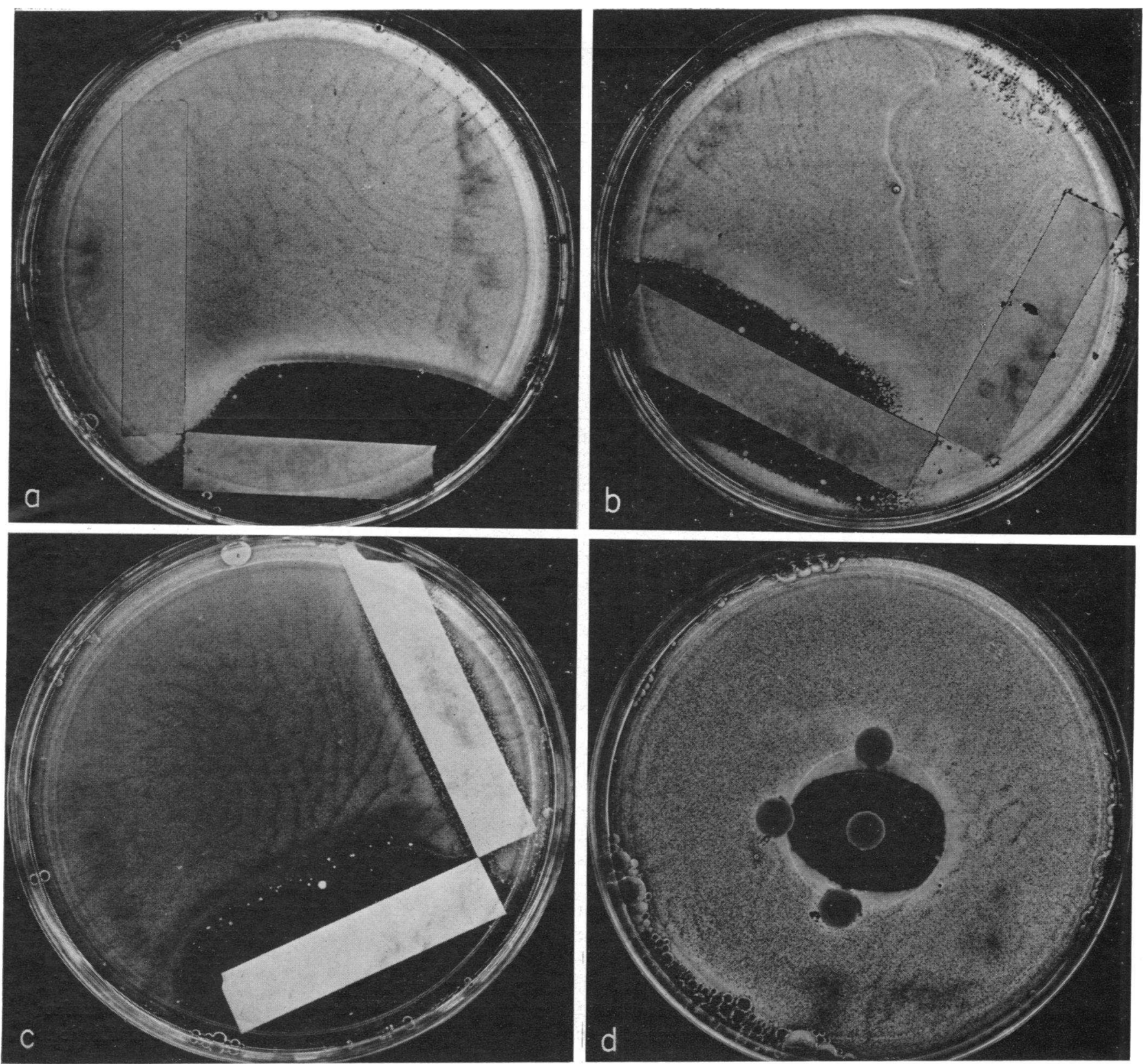

FIGURE 4 (a) Antagonism of the action of carbenicillin $(100 \mu \mathrm{g} / \mathrm{ml}$ in paper strip at bottom) by 6 -aminopenicillanic acid $(50 \mu \mathrm{g} / \mathrm{ml}$ in paper strip at left). E. coli is the organism growing on surface of plate. (b) P. rettgeri on surface of agar plate; inhibitory activity of BLP 1654 $(100 \mu \mathrm{g} / \mathrm{ml}$ in paper strip on left) is antagonized by 6-aminopenicillanic acid (at $50 \mu \mathrm{g} / \mathrm{ml}$ diffusing from strip on right), which by itself causes no zone of inhibition. (c) P. aeruginosa I on surface of agar plate; inhibitory activity of carbenicillin $(100 \mu \mathrm{g} / \mathrm{ml}$ in paper strip at bottom) is antagonized by 6 -aminopenicillanic acid $(1,000 \mu \mathrm{g} / \mathrm{ml}$ in paper strip, upper right), which is causing only slight inhibition by itself. $(d) E$. coli on surface of agar plate; the antibacterial effect of carbenicillin (center disk containing $100 \mu \mathrm{g}$ ) is antagonized by cephalothin (CF, bottom disk with $30 \mu \mathrm{g}$ ) and by 6-aminopenicillanic acid (top disk [no letters] $500 \mu \mathrm{g}$ ), but not by oxacillin (disk on left, $500 \mu \mathrm{g}$ ). 
TABLE II

Induction of $\beta$-Lactamase in E. coli and P. rettgeri

\begin{tabular}{|c|c|c|c|c|}
\hline \multirow[b]{2}{*}{ Enzyme source } & \multirow[b]{2}{*}{ Inducer } & \multirow{2}{*}{$\begin{array}{c}\text { Inducer } \\
\text { concentration* }\end{array}$} & \multirow[b]{2}{*}{ Enzyme activity } & \multirow{2}{*}{$\frac{\text { Activity }}{\text { Control activity }}$} \\
\hline & & & & \\
\hline & & $\mu g / m l$ & $\begin{array}{l}\text { Amol benzylpenicillin } \ddagger \\
\text { hydrolyzed/mg/h }\end{array}$ & \\
\hline \multirow[t]{5}{*}{ E. coli } & Benzylpenicillin & 625 & 66 & 2.8 \\
\hline & 6-APA & 32 & 259 & 10.8 \\
\hline & Carbenicillin & 8 & 52 & 2.2 \\
\hline & Cephaloridine & 250 & 21 & 0.9 \\
\hline & No inducer & - & 24 & 1.0 \\
\hline \multirow[t]{5}{*}{ P. rettgeri } & Benzylpenicillin & 500 & 149 & 2.9 \\
\hline & 6-APA & 250 & 231 & 4.4 \\
\hline & Carbenicillin & 8 & 57 & 1.1 \\
\hline & Cephaloridine & 250 & 167 & 3.2 \\
\hline & No inducer & 一 & 52 & 1.0 \\
\hline
\end{tabular}

* Concentration inducer selected was one-half the MIC of the antibiotic for the indicated organism. At 10 $\mu \mathrm{g} / \mathrm{ml}, 6$-aminopenicillanic acid (6-APA), benzylpenicillin, and cephaloridine did not affect induction. $\ddagger$ Negligible hydrolysis was detectable with carbenicillin as substrate (activity measured in supernatant fluid from sonicated cells; activity as micromoles benzylpenicillin hydrolyzed per milligram protein per hour.

Antagonism of carbenicillin by cephaloridine and by 6-aminopenicillanic acid is shown in Fig. 4, in which the test organism was flooded on heart infusion agar. In each figure the zone of inhibition (no growth of bacteria) around the paper strip containing carbenicillin or BLP 1654 is reduced or obliterated in the vicinity of the neighboring paper strip or disks from which the antagonizing antibiotic is diffusing.

The production of $\beta$-lactamase (E.C. 5.1.2.6) by $E$. coli and $P$. rettgeri in the absence and presence of various inducers is shown in Table II. Although 6-aminopenicillanic acid was the best inducer of $\beta$-lactamase in both organisms when benzylpenicillin was used as substrate, no activity was detected when carbenicillin was used as substrate. When whole bacteria (rather than crude enzyme) were incubated with carbenicillin alone or with carbenicillin and cephaloridine or 6-aminopenicillanic acid (at optimal antagonistic concentrations, as in Figs. 1-3), there was no accelerated inactivation of carbenicillin when cephaloridine or 6-aminopenicillanic acid was also present (Fig. 5).

Additional evidence that the production of $\beta$-lactamase in $P$. rettgeri is inducible is shown in Fig. 6 . Note that the inducing concentration of 6-aminopenicillanic acid $(100 \mu \mathrm{g} / \mathrm{ml})$ was not associated with antagonism of carbenicillin (Fig. 3) but that lower concentrations (that did not induce $\beta$-lactamase synthesis) were antagonistic.

\section{DISCUSSION}

The demonstrated antagonism of some penicillins by other penicillins and cephalosporins is remarkable in that only low concentrations of the antagonists produce the phenomenon, i.e., concentrations one-fourth or less of the MIC and, in the most extreme example ( $\mathrm{Ta}$ ble I) with $P$. morgani, one-twentieth of the MIC of 6-aminopenicillanic acid will increase the amount of carbenicillin required for inhibition to 64 times its MIC. Possible explanations for the antagonism are: (a) The antagonist induces $\beta$-lactamase which inactivates the more active antibiotic, thus causing an apparent increase in its MIC. (b) The antagonist combines with $\beta$-lactamase, increasing its efficiency (rate of hydrolysis of the antagonized antibiotic), thus leading to an increase in MIC. (c) The antagonist prevents the more active antibiotic from reaching a binding site on the bacterium that is critical for causing the antibiotic effect, without producing the antibiotic action itself. This could be a result of the antagonist attaching either on the key binding site itself, or near it. (d) The antagonist could induce a biological change in the bacterial surface that impeded attachment of the more active antibiotic to its binding site.

The first possibility seems to be excluded by the fact that cephaloridine was not a good inducer of $\beta$-lactamase in $E$. coli and that 6-aminopenicillanic acid although a good inducer of $\beta$-lactamase (with benzylpenicillin as substrate in both $E$. coli and $P$. rettgeri) did not lead to increased inactivation of carbenicillin by either whole cells or by cell-free (crude) enzyme preparations from cells exposed to 6-aminopenicillanic acid.

The second possibility seems excluded by the finding that adding 6-aminopenicillanic acid or cephaloridine 


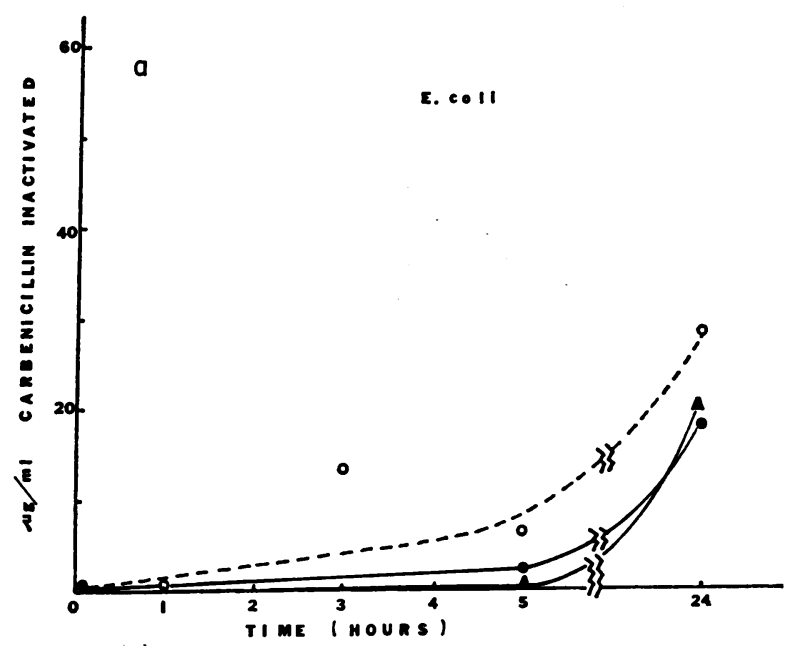

to preformed $\beta$-lactamase did not increase its activity (with benzylpenicillin as substrate); activity with carbenicillin as substrate could not be demonstrated.

The third and fourth possibilities were not tested and remain possibilities. To properly test for blockage of attachment of the more active antibiotic (usually carbenicillin or BLP 1654 , but also ampicillin) it would be necessary to have radioactive compounds with suffcient specific activity to be detected with the relatively few molecules of penicillin that attach per cell (3), and we have not had such labeled compounds available. To establish the fourth possibility, it would be necessary to prove the cell wall and/or membrane were changed, in a way that functionally decreased binding of the more active compound. This proof would require both chemical analyses and evidence regarding binding, which
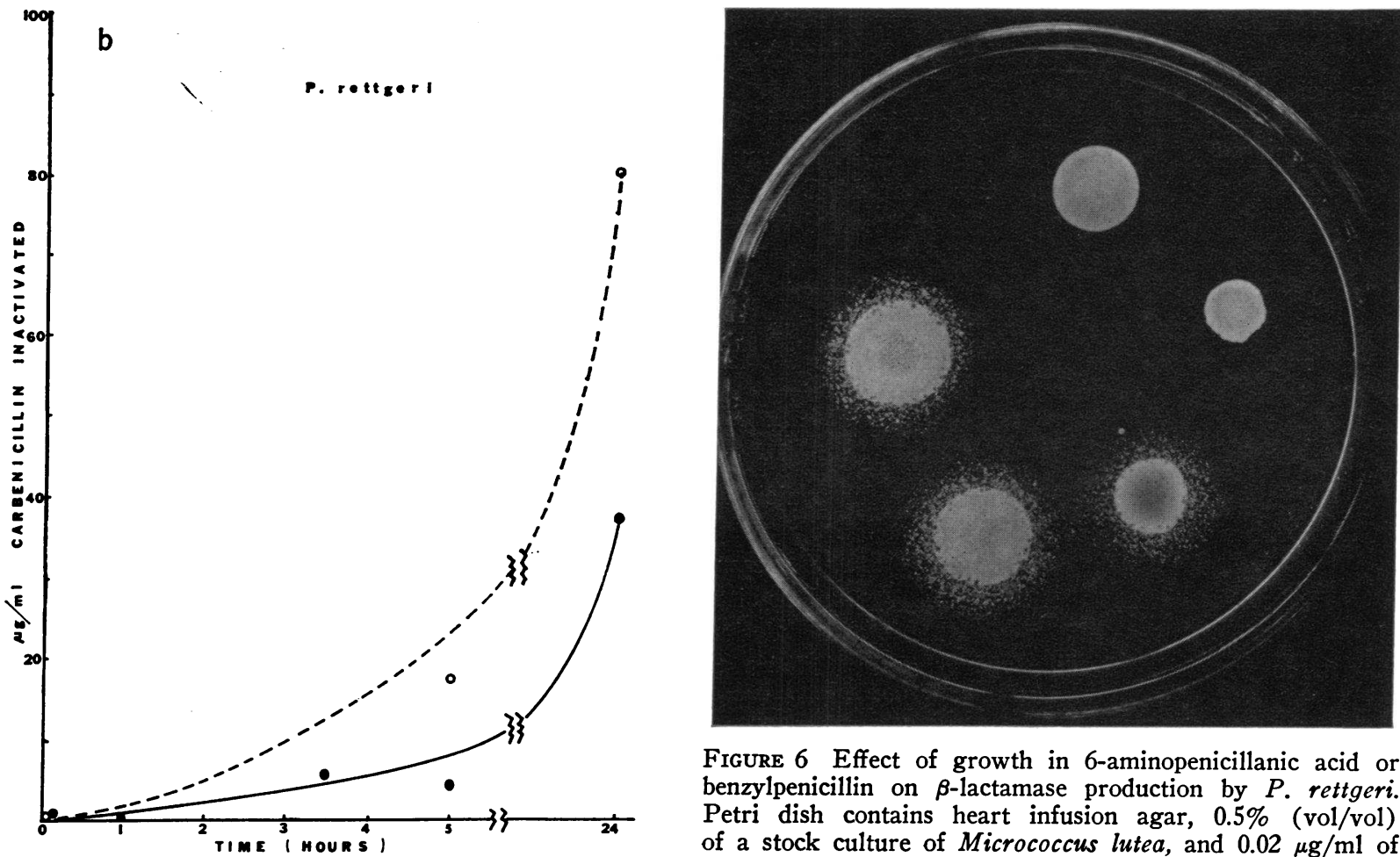

FIGURE 6 Effect of growth in 6-aminopenicillanic acid or benzylpenicillin on $\beta$-lactamase production by $P$. rettgeri. Petri dish contains heart infusion agar, $0.5 \%$ (vol/vol) of a stock culture of Micrococcus lutea, and $0.02 \mu \mathrm{g} / \mathrm{ml}$ of benzylpenicillin (enough to inhibit the $M$. lutea but not the $P$. rettgeri). Small circles of the $P$. rettgeri were streaked on surface after overnight growth in brain heart infusion broth containing no antibiotic (top), $10 \mu \mathrm{g}$ 6-aminopenicillanic acid $/ \mathrm{ml}$ (next circular colony clockwise, at about 2 o'clock), $100 \mu \mathrm{g}$ 6-aminopenicillanic acid/ml (at 5 o'clock), 1,000 $\mu \mathrm{g}$ benzylpenicillin/ml (at 7 o'clock), or $2,000 \mu \mathrm{g}$ benzylpenicillin/ml (at 9 o'clock). The plate was incubated $48 \mathrm{~h}$ at $37^{\circ} \mathrm{C}$ and photographed. Halos of $M$. lutea growing around last three circles indicate concentration of antibiotic in agar has fallen below inhibitory concentration $(<0.006 \mu \mathrm{g} / \mathrm{ml})$ for $M$. lutea. Absence of halos around cells that had not been previously exposed to antibiotic, or only at lowest concentration, indicates inactivating mechanism ( $\beta$-lactamase) is inducible by higher concentrations. 1 . $O$, carbenicillin only antibiot $(16 \mu \mathrm{g} / \mathrm{ml})$ in culture. 
would also require radioactive penicillins with sufficient specific activity as for the third possibility.

The biphasic nature of the isobolograms suggests there are at least two critical penicillin binding sites. The one that is probably most susceptible to carbenicillin or BLP 1654 is apparently responsible for the antibacterial activity of these more active antibiotics; it is apparently the one that is blocked by the antagonizing substances. As the concentration of the antagonizing substance is increased (to the right of the peak of the isobols in Figs. 1-3) the isobols show an additive effect, indicated by a straight line (9-11) (Figs. 1 and 2), or slight synergy, indicated by the modest bowing downward of the portion of the isobol beyond the peak in Fig. 3 (9-11). The implication is thus that the more susceptible binding site is successfully attacked by low concentrations (e.g., $8 \mu \mathrm{g} / \mathrm{ml}$ ) of carbenicillin or BLP 1654 when they are acting alone. However, relatively low concentrations of cephaloridine or 6-aminopenicillanic acid (at one-twentieth their MIC's) apparently block that sensitive site, possibly completely, and the carbenicillin or BLP 1654, if it is to act at all, must attack a less sensitive site, resulting in an MIC of 128 or $256 \mu \mathrm{g} / \mathrm{ml}$. But if additional cephaloridine or 6-aminopenicillanic acid is added (to the right of the peak of the isobols) less carbenicillin, or BLP 1654, is required to inhibit the organisms, for the pairs of antibiotics that are antagonistic on the more sensitive site (to the left of the isobol peak) act together either additively or slightly synergistically on the less sensitive binding site, represented by the points to the right of the isobol peak.

The existence of multiple binding sites for penicillins on membranes from Bacillus subtilis has been reported by Blumberg and Strominger $(18,19)$. The present studies provide evidence that two or more binding sites probably exist on these gram-negative bacilli and that they have very different functional susceptibilities to some penicillins. It has been implied (18) that most bacteria have more than one penicillin binding site; the apparent MIC is a result of the most susceptible binding site (penicillin-susceptible enzymes $[1,2]$ ) being attacked, but if there is a mutation toward resistance of the most susceptible site, the MIC increases to that concentration that works on the next-most-susceptible site. The "stepwise" increase in resistance seen when penicillin-susceptible strains are grown in the laboratory in the presence of gradually increasing penicillin concentrations could be explained by this postulate. The data presented here suggest these postulated differences in susceptibility of different sites on the same organism exist, and can be demonstrated dramatically with appropriate blockade of the most susceptible site.

Although some antagonism of penicillins by other penicillins has been reported in the past $(20,21)$, the degree was not as great as is described here. The antagonism in those reports was for Enterobacter cloacae (20) and Staphylococcus albus (21). The possibility that this interpenicillin antagonism, mainly of carbenicillin, may occur in clinical medicine should not be overlooked; some patients receiving carbenicillin for a pseudomonas infection may also be receiving cephaloridine for a concomitant Staphylococcus aureus infection.

\section{ACKNOWLEDGMENTS}

This work was supported in part by grants $5 \mathrm{R}-1-\mathrm{AI}-23$ and 2T01-AI-68 from the National Institute of Allergy and Infectious Diseases, grant 711007 from the American Heart Association, and a grant from the Milton Fund of Harvard University.

\section{REFERENCES}

1. Wise, E. M., Jr., and J. T. Park. 1965. Penicillin: its basic site of action as an inhibitor of a peptide crosslinking reaction in cell wall mucopeptide synthesis. Proc. Natl. Acad. Sci. U. S. A. 54: 75-81.

2. Tipper, D. J., and J. L. Strominger. 1965. Mechanism of action of penicillins: a proposal based on their structural similarity to acyl-d-alanyl-D-alanine. Proc. Natl. Acad. Sci. U.S. A. 54: 1133-1141.

3. Edwards, J. R., and J. T. Park. 1969. Correlation between growth inhibition and the binding of various penicillins and cephalosporins to Staphylococcus aureus. J. Bacteriol. 99 : 459-462.

4. Sabath, L. D., and E. P. Abraham. 1964. Synergistic action of penicillins and cephalosporins against Pseudomonas pyocyanea. Nature (Lond.). 204: 1066-1069.

5. Sutherland, R., and F. R. Batchelor. 1964. Synergistic activity of penicillins against penicillinase-producing Gram-negative bacilli. Nature (Lond.). 201: 868-869.

6. Hamilton-Miller, J. M. T., J. T. Smith, and R. Knox. 1964. Effect of penicillinase on the activity of penicillins. Potentiation of penicillin action by inhibition of penicillinase. Nature (Lond.). 201: 867-868.

7. Sabath, L. D., H. A. Elder, C. E. McCall, and M. Finland. 1967. Synergistic combinations of penicillins in the treatment of bacteriura. N. Engl. J. Med. 277: 232-238.

8. Sabath, L. D., M. Jago, and E. P. Abraham. 1965. Cephalosporinase and penicillinase activities of a $\beta$ lactamase from Pseudomonas pyocyanea. Biochem. J. $96: 739-752$.

9. Sabath, L. D. 1968. Synergy of antibacterial substances by apparently known mechanisms. Antimicrob. Agents Chemother.-1967. 210-217.

10. Loewe, S. 1953. The problem of synergy and antagonism of combined drugs. Arzneim-Forsch. 3: 285-290.

11. Lacey, B. W. 1958. Mechanisms of chemotherapeutic synergy. Symp. Soc. Gen. Microbiol. 8: 247-287.

12. Heatley, N. G. 1944. A method for the assay of penicillin. Biochem. J. 38: 61-65.

13. Haight, T. H., and M. Finland. 1952. Modified Gots test for penicillinase production. Am. J. Clin. Pathol. 22: 806-808.

14. Gots, J. S. 1945. The detection of penicillinase-producing properties of microorganisms. Science (Wash. D.C.). 102: 309.

15. Henry, R. J., and R. D. Housewright. 1947. Studies on penicilinases. II. Manometric method of assaying peni- 
cillinase and penicillin kinetics of the penicillin-penicillinase reaction, and the effects of inhibitors. J. Biol. Chem. $167: 559-571$.

16. Pollock, M. R. 1952. Penicillinase adaptation in Bacillus cereus: an analysis of three phases in the response of logarithmically growing cultures to induction of penicillinase formation by penicillin. Br.J. Exp. Pathol. 33: $587-600$.

17. Lowry, O. H., N. J. Rosebrough, A. L. Farr, and R. J. Randall. 1951. Protein measurement with the Folin phenol reagent. J. Biol. Chem. 193: 265-275.

18. Blumberg, P. M., and J. L. Strominger. 1972. Isolation by covalent affinity chromatography of the penicillinbinding components from membranes of Bacillus subtilis. Proc. Natl. Acad. Sci. U. S. A. 69: 3751-3755.

19. Blumberg, P. M., and J. L. Strominger. 1972. Five penicillin-binding components occur in Bacillus subtilis membranes. J. Biol. Chem. 247: 8107-8113.

20. Seligman, S. J. 1968. Antagonism between penicillin combinations. Clin. Res. 16: 335. (Abstr.)

21. Annear, D. I., and T. C. Nortcott. A note on interactions between methicillin and other penicillins in disc sensitivity tests of Staphylococcus epidermidis. Med. J. Aust. 1: 661-663. 